\title{
APLICAÇÃO DO MÉTODO WTF NO ESTUDO DA VARIABILIDADE DA RECARGA EM AQUÍFERO URBANO
}

\author{
APPLICATION OF THE WTF METHOD IN THE STUDY OF RECHARGE VARIABILITY IN \\ URBAN AQUIFER
}

\author{
Camila Angélica BAUM ${ }^{1}$, Malva Andrea MANCUSO ${ }^{2}$, Rafael Renato FRITZEN ${ }^{3}$ \\ ${ }^{1}$ Universidade do Estado de Santa Catarina - UDESC. Email: eng.camilabaum@gmail.com \\ ${ }^{2}$ Departamento de Engenharia e Tecnologia Ambiental, da Universidade Federal de Santa Maria - UFSM, Campus Frederico \\ Westphalen. Email: malvamancuso@ufsm.br \\ ${ }^{3}$ Universidade Federal de Santa Maria - UFSM. Email: rrfritzen@gmail.com
}

\author{
Introdução \\ Área de estudo \\ Metodologia \\ Monitoramento pluviométrico \\ Monitoramento hidrogeológico \\ Estimativa da recarga direta \\ Resultados e discussão \\ Conclusões \\ Referências
}

\begin{abstract}
RESUMO - A expansão dos espaços urbanos causa diversos impactos ao meio ambiente, sendo a alteração da recarga de aquíferos um dos componentes hidrológicos mais afetados. Apesar do aporte de recarga por fontes não contínuas, como vazamentos de águas de abastecimento e esgoto, a impermeabilização provoca diminuição das áreas permeáveis, dificultando a infiltração das águas pluviais. O presente trabalho visa estimar a recarga direta (reserva reguladora) de origem natural em área urbana e avaliar sua variabilidade espacial, utilizando como estudo de caso a cidade de Frederico Westphalen. A estimação da recarga foi realizada para o período de um ano, por meio da aplicação do método WTF, utilizando dados de monitoramento pluviométrico e o monitoramento hidrogeológico, realizado com periodicidade mensal em treze poços localizados em lotes urbanos. A recarga total estimada na área foi de aproximadamente $283,58 \mathrm{~mm} /$ ano, correspondendo a $11,57 \%$ da precipitação total $(2.450 \mathrm{~mm})$, sendo observado que, quanto maior a espessura da camada não saturada, maior a taxa de recarga quantificada. Os resultados apresentados fornecem subsídios para a gestão das águas pluviais urbanas, além de demostrarem a necessidade urgente de ampliação e preservação das áreas permeáveis em zonas urbanas.
\end{abstract}

Palavras-chave: Recarga, Águas Subterrâneas, Método WTF, Aquífero Urbano.

\begin{abstract}
The expansion of the urban areas causes several environmental impacts, being the changing of the aquifers recharge one of the most affected hydrological components. Despite the recharge contribution by non-continuous sources, such as leaks of water supply and drainage, waterproofing causes decrease in permeable areas, hindering the infiltration of the rainwater. This study aims to estimate the direct recharge (regulator reserve) of natural origin in urban area and evaluate their spatial variability, using as case study of the town of Frederico Westphalen. The estimation of the recharge was realized for the period of one year, through the application of the WTF method, using rainfall monitoring data and hydrogeological monitoring, realized with a monthly basis in thirteen wells located in urban lots. The total estimated recharge in the area was approximately 283,58 mm / year, corresponding to $11,57 \%$ of the total precipitation $(2450,22 \mathrm{~mm})$, it was observed that, the higher the unsaturated layer thickness, the greater the recharge rate quantified. The results presented provide subsidies for the management of urban stormwater, besides demonstrating the urgent need for expansion and preservation of the permeable areas in urban areas.
\end{abstract}

Keywords: Recharge, Groundwater, WTF Method, Urban Aquifer.

\section{INTRODUÇÃO}

A recarga de água subterrânea é o componente mais difícil de determinação do ciclo hidrológico, além de suas estimativas apresentarem alto grau de incerteza devido, principalmente, às dúvidas na aplicação de metodologias que permitam a medição direta da recarga, à influência de fatores como o uso e ocupação do solo e às intervenções humanas que afetam a taxa de recarga (Healy, 2010; Wendland et al., 2015). A crescente expansão dos centros urbanos e as alterações causadas por essa tendência alteram severamente a dinâmica hidrogeológica local que, numa perspectiva de futuro sustentável deveria considerar nas suas diretrizes de desenvolvimento os impactos provocados pela urbanização na geologia e hidrologia local (Hibbs \& Sharp, 2012).

No caso da recarga de origem natural, a quantificação da recarga torna-se complexa devido às intervenções humanas no uso do solo, que leva ao aumento de áreas impermeabilizadas e consequentemente à redução da infiltração das águas pluviais. Em contrapartida, observa-se um aporte de recarga derivado de fontes introduzidas pela urbanização, como vazamentos das redes de esgoto e das redes de abastecimento de água, que incrementam a recarga subterrânea e modificam a trajetória da água precipitada 
(Maziero \& Wendland, 2008; Lerner, 2002).

De acordo com Lerner (2002), os aportes de recarga antrópica se apresentam como fontes contínuas, de difícil quantificação, que não causam flutuações episódicas no nível de água. A quantificação da recarga individual por componentes (recarga direta, vazamento de água, fossas sépticas, etc.) permite a quantificação da recarga antrópica, diferentemente da quantificação da recarga de forma holística, a qual quantifica a recarga total do sistema (Lerner, 2002). No entanto, ambas as abordagens apresentam diversas incertezas e complexidade.

As variações observadas no nível freático são oriundas de recarga de fontes não contínuas, como a precipitação, sendo esta a principal fonte de recarga natural dos aquíferos (Lerner, 2002). As águas de infiltração de origem não contínua, ao atingirem o nível freático entram no armazenamento do sistema, compondo sua reserva reguladora (Feitosa, 2008). Por razões econômicas e de gestão é importante o conhecimento da dinâmica da água e a quantificação da reserva reguladora, pois esta contribui para o sistema de fluxo regional subterrâneo e superficial, e se apresenta como um recurso importante para o abastecimento público. Wendland et al. (2015) destacam que uma parcela importante das águas recarregadas pode escoar em profundidade, alimentando aquíferos subjacentes ao sistema livre.

A inexistência de um método que permita a medição direta da recarga de águas subterrâneas e a complexidade que envolve a estimativa da mesma instigaram o desenvolvimento distintos métodos para a estimativa da recarga nas mais diversas escalas de tempo e espaço, como propostos por Maziero \& Wendland (2008), Martelli (2012), Wendland et al. (2015) e Lerner (2002).

No entanto, entre as técnicas mais utilizadas para estimativa da recarga em aquífero livre cita-se o Método WTF (Water Table Fluctuation) ou Método da Flutuação do Nível Freático, que se destaca pela simplicidade na estimativa das taxas de recarga direta, por meio da avaliação das flutuações temporais e padrões espaciais dos níveis de águas subterrâneas (Healy \& Cook, 2002).

O Método WTF baseia-se em medições dos níveis freáticos em poços de monitoramento por um período de tempo pré-determinado. Esse método está fundamentado na premissa de que as alterações no nível freático estão relacionadas com as mudanças na quantidade de água armazenada no aquífero, considerando que a água precipitada, após percolar no solo, atinge o nível freático. O método apresenta melhores resultados quando aplicado a aquíferos livres, em função da rápida resposta deste tipo de aquífero aos eventos de precipitação (Healy \& Cook, 2002; Delin et al., 2007; USGS, 2007).

O método WTF considera que, quando a água atinge o nível freático entra imediatamente em armazenamento e que todos os outros componentes do balanço hídrico subterrâneo são nulos durante o período de recarga, a exceção da descarga que é considerada a partir da extrapolação da curva de recessão do nível freático. Para que a aplicação do método seja possível é necessário o conhecimento do rendimento específico (Sy), das variações do nível freático ao longo do tempo $(\Delta H)$ (Healy \& Cook, 2002) e a precipitação do período considerado $(\mathrm{P})$.

Embora simples em teoria, o Método WTF possui alguns pressupostos fundamentais que influenciam no sucesso da sua aplicação, sendo estes: o hidrogramas, que retrata apenas flutuações do nível freático causadas por recarga originária de fontes não contínuas, como a precipitação (Lerner 2002; USGS, 2007), o Sy é conhecido e constante ao longo do período de tempo das flutuações do nível freático, e a $\Delta H$ que considera a pré-recarga no nível da água como sendo equivalente à descarga de água subterrânea obtida a partir da extrapolação da curva de recessão (comportamento do nível freático durante a estiagem prévia ao evento de recarga) (USGS, 2007).

A cidade de Frederico Westphalen, localizada na região Noroeste do estado do Rio Grande do Sul, apresentou mais de $100 \%$ de expansão da sua área urbana nas últimas décadas, sendo que mais de $70 \%$ da superfície do perímetro urbano foi impermeabilizada por construções, edifícios e vias asfaltadas (Baum, 2015).

A alta taxa de impermeabilização implica não somente em problemas na drenagem urbana 
da cidade, conforme relatado por Arboit (2014), mas também dificulta a recarga natural do aquífero, que está localizado em zonas de nascentes da bacia hidrográfica do Rio da Várzea (Baum, 2015). Lima et al. (2013) alertaram que a antropização em áreas de recarga com presença de nascentes altera o sistema hídrico, causando a redistribuição inadequada da água.

O objetivo deste trabalho foi estimar a recarga direta (reserva reguladora) de origem natural (não contínua) na área urbana de Frederico Westphalen e avaliar sua variabilidade espacial. No desenvolvimento metodológico foram utilizados dados hidrológicos e pluviométricos para aplicação do método Water Table Flutuation (WTF), a fim de verificar a interferência da impermeabilização na recarga natural, como subsídio à elaboração de diretrizes municipais para a gestão de uso e ocupação do solo na área urbana.

\section{ÁREA DE ESTUDO}

O estudo foi realizado na área urbana da cidade de Frederico Westphalen, localizada na bacia hidrográfica do Rio da Várzea, no noroeste do Estado do Rio Grande do Sul. A área urbanizada está situada entre as coordenadas $27^{\circ} 20^{\prime} 55^{\prime \prime}$ S e $27^{\circ} 20^{\prime} 44^{\prime \prime} \mathrm{S}$, e $53^{\circ} 23^{\prime} 58^{\prime \prime} \mathrm{W}$ e $53^{\circ} 23^{\prime} 53^{\prime \prime} \mathrm{W}$, sobre os divisores de água das bacias Lajeado Chiquinha, Lajeado Perau, Rio Pardo e Lajeado Mico (Figura 1).

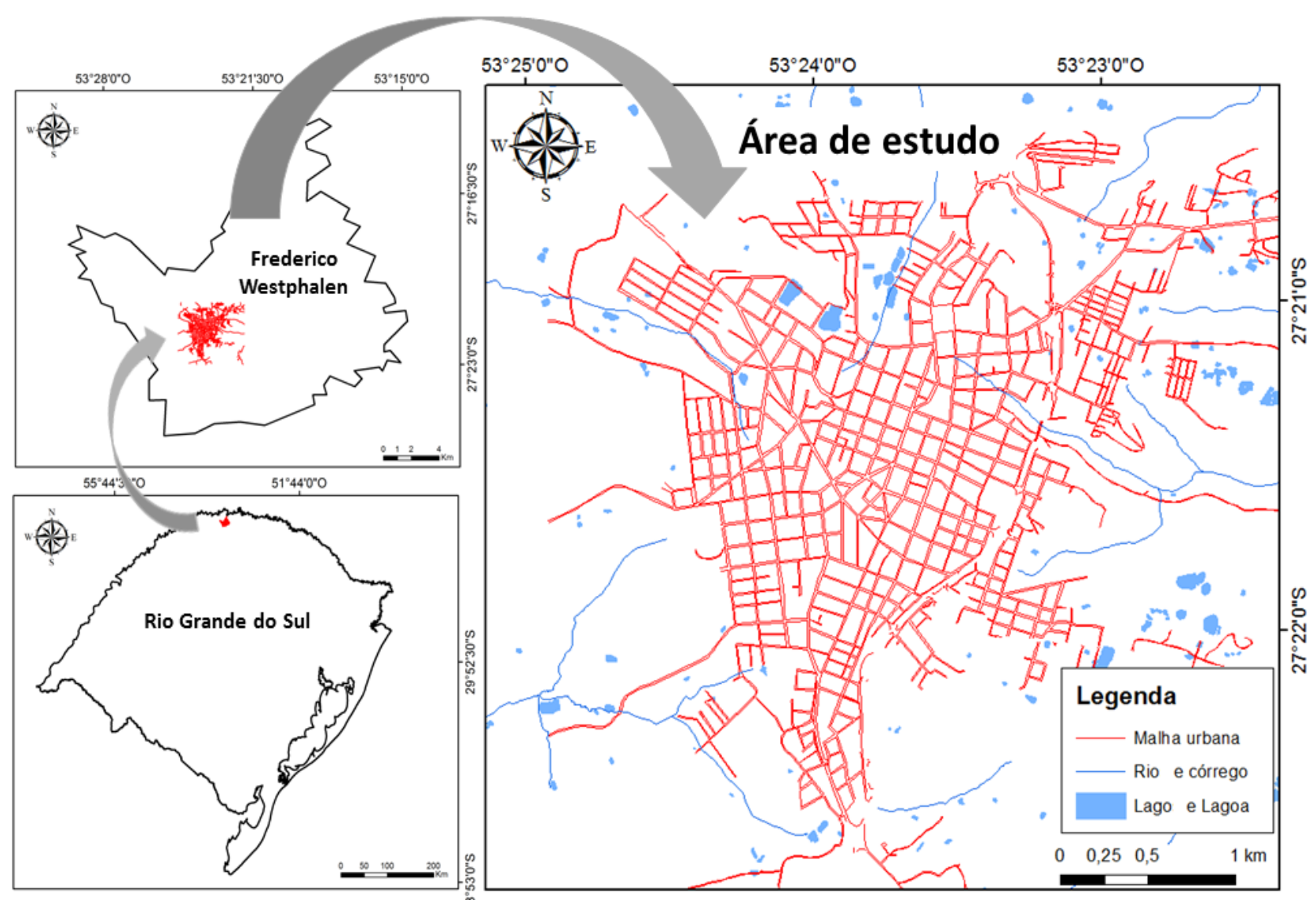

Figura 1 - Localização da área urbana de Frederico Westphalen, no Estado do Rio Grande do Sul.

A área urbana de Frederico Westphalen ocupa atualmente $5,66 \mathrm{~km}^{2}$, apresentando um crescimento da ordem de 109,05\% entre 1987 e 2011 (Bertani et al., 2012). De acordo com e Flores (2014) e Baum (2015), o uso e ocupação do solo no perímetro urbano da cidade é intenso, constatando que os lotes possuem aproximadamente $70 \%$ de sua área coberta por usos impermeáveis e que apenas 13,8\% possuem condições satisfatórias para a infiltração, o que demonstra a necessidade urgente de ampliação e preservação das áreas permeáveis.

No contexto geológico, a cidade está localizada sobre o Sistema Aquífero Serra Geral (SASG). De acordo com Machado \& Freitas (2005) o SASG é regionalmente um aquífero com 
porosidade por fraturas e possui elevada potencialidade devido ao seu condicionamento geológico.

Na área de estudo, observa-se uma zona saturada na porção intemperizada dos basaltos da Formação Serra Geral, que se configura em zona de recarga, com características de aquífero livre.

A espessura aproximada desse sistema livre é de até $24 \mathrm{~m}$, de acordo com as medições de profundidade dos poços de monitoramento utilizados neste estudo, que são do tipo cacimba, com escavação na porção intemperizada da rocha.

O clima da região, segundo a classificação de Köppen, é temperado úmido com verão quente (Cfa), e apresenta dois períodos térmicos distintos ao longo do ano: um, com temperatura média superior a $20{ }^{\circ} \mathrm{C}$, durante os meses de novembro, dezembro, janeiro e fevereiro (verão), e outro, com temperatura média inferior a $15{ }^{\circ} \mathrm{C}$, nos meses de junho, julho e agosto (inverno).

A cidade apresenta elevada precipitação média anual, bem distribuída ao longo do ano, com média aproximada de $2.400 \mathrm{~mm} / \mathrm{ano}$ (entre 2012 e 2016).

Os meses com maior incidência pluviométrica são abril $( \pm 270 \mathrm{~mm})$, dezembro $( \pm 260$ $\mathrm{mm})$ e outubro ( $\pm 230 \mathrm{~mm})$, enquanto os meses mais secos são agosto $( \pm 125 \mathrm{~mm})$, setembro $( \pm 140 \mathrm{~mm})$ e fevereiro $( \pm 160 \mathrm{~mm})$, indicando que a precipitação é bem distribuída ao longo do ano.

\section{MATERIAIS E MÉTODO}

O método WTF foi utilizado nesse estudo, por ser um dos mais empregados para estimar a recarga de fontes não contínuas em aquíferos livres localizados em áreas urbanas. Para a aplicação do método foi necessário o desenvolvimento das seguintes etapas: 1) monitoramento pluviométrico; 2) monitoramento hidrogeológico; e 3) estimativa da recarga direta. A seguir descrevem-se, detalhadamente, cada uma dessas etapas.

\section{Monitoramento Pluviométrico}

O monitoramento pluviométrico foi realizado a partir do registro de precipitação, com variação temporal de uma hora, obtido na Estação Meteorológica Automática de Frede- rico Westphalen (INMET, 2015), que está localizada nas coordenadas geográficas de referência de $53^{\circ} 25^{\prime} 46^{\prime \prime}$ W e $27^{\circ} 23^{\prime} 44^{\prime \prime}$ S, a $489 \mathrm{~m}$ do nível do mar e distante $5,20 \mathrm{~km}$ do centro da área de estudo.

Para análise dos dados pluviométricos foram realizadas as somas do total precipitado a cada período de trinta dias, correspondentes aos intervalos entre as medições de N.A., durante um ano hidrológico, de fevereiro de 2014 a fevereiro de 2015. Esses dados foram compara-dos com as taxas de recarga mensal, sendo considerada a soma do total precipitado no período dos trinta dias antecedentes a medição do N.A.

Tabela 1 - Descrição dos poços monitorados na área urbana da cidade de Frederico Westphalen.

\begin{tabular}{|c|c|c|c|c|c|}
\hline \multirow{2}{*}{ Poço FW } & \multicolumn{2}{|c|}{ UTM 22S* } & \multirow{2}{*}{$\begin{array}{c}\text { Cota } \\
\text { Topográfica (m) }\end{array}$} & \multirow{2}{*}{$\begin{array}{c}\text { Profundidade do } \\
\text { Poço (m) }\end{array}$} & \multirow{2}{*}{$\begin{array}{l}\text { Cota Piezométrica } \\
\text { Mínima do N.A. (m) }\end{array}$} \\
\hline & Latitude & Longitude & & & \\
\hline FW 01 & 263753 & 6971830 & 505 & 1,83 & 504,07 \\
\hline FW 02 & 263263 & 6972591 & 535 & 2,21 & 534,11 \\
\hline FW 03 & 262312 & 6972612 & 560 & 0,82 & 559,76 \\
\hline FW 04 & 262685 & 6970885 & 520 & 3,45 & 519,14 \\
\hline FW 05 & 263313 & 6971742 & 530 & 3,05 & 528,82 \\
\hline FW 06 & 263315 & 6971531 & 520 & 3,35 & 517,70 \\
\hline FW 07 & 263207 & 6971039 & 540 & 7,75 & 535,55 \\
\hline FW 08 & 262791 & 6971187 & 525 & 7,99 & 519,84 \\
\hline FW 09 & 262392 & 6972441 & 565 & 8,17 & 557,73 \\
\hline FW 10 & 262472 & 6970974 & 540 & 8,35 & 533,02 \\
\hline FW 11 & 262570 & 6971535 & 545 & 8,68 & 537,65 \\
\hline FW 12 & 262869 & 6971850 & 560 & 13,16 & 549,05 \\
\hline FW 13 & 262688 & 6972024 & 559 & 22,38 & 539,93 \\
\hline
\end{tabular}




\section{Monitoramento Hidrogeológico}

O monitoramento hidrogeológico consistiu na medição de níveis da água subterrânea (N.A.) na zona de intemperismo dos basaltos, no período correspondente a um ano hidrológico, de fevereiro de 2014 a fevereiro de 2015. As medições foram realizadas em treze (13) poços do tipo cacimba, localizados na área urbana de Frederico Westphalen (Tabela 1, Figura 2).

As medições do nível d'água foram realizadas uma vez por mês, utilizando como instrumento de medição um Medidor de Nível d’Água, marca Solinst - Modelo 101, comprimento total de $50 \mathrm{~m}$.

A seleção dos poços de monitoramento foi realizada com base na profundidade dos poços cacimba (totalmente penetrantes na zona de intemperismo do basalto) e na distribuição representativa das áreas de cabeceira, divisores de águas e nascentes dos córregos Lajeado Chiquinha, Lajeado Perau, Rio Pardo e Lajeado Mico, localizadas dentro do perímetro urbano de Frederico Westphalen.

A variação do nível de água do aquífero e a estimativa da espessura da zona não saturada (profundidade do N.A.) permitem a identificação de áreas potenciais para infiltração e retenção de águas pluviais na zona urbana. Para identificar as zonas potenciais de interesse para a retenção de águas de infiltração, foi elaborado o mapa potenciométrico com indicação dos fluxos das águas subterrâneas e o mapa de espessuras não saturada do aquífero freático. O mapa potenciométrico foi elaborado a partir dos dados de profundidade do nível de água subterrânea coletados no mês de outubro de 2014, nos poços de monitoramento e em outros poços cacimba existentes na área urbana (poços extras denominados de "E”, que também captam água do aquífero freático); assim como de dados das zonas naturais de descarga, obtidas com o cadastramento das nascentes (Tabela 2).

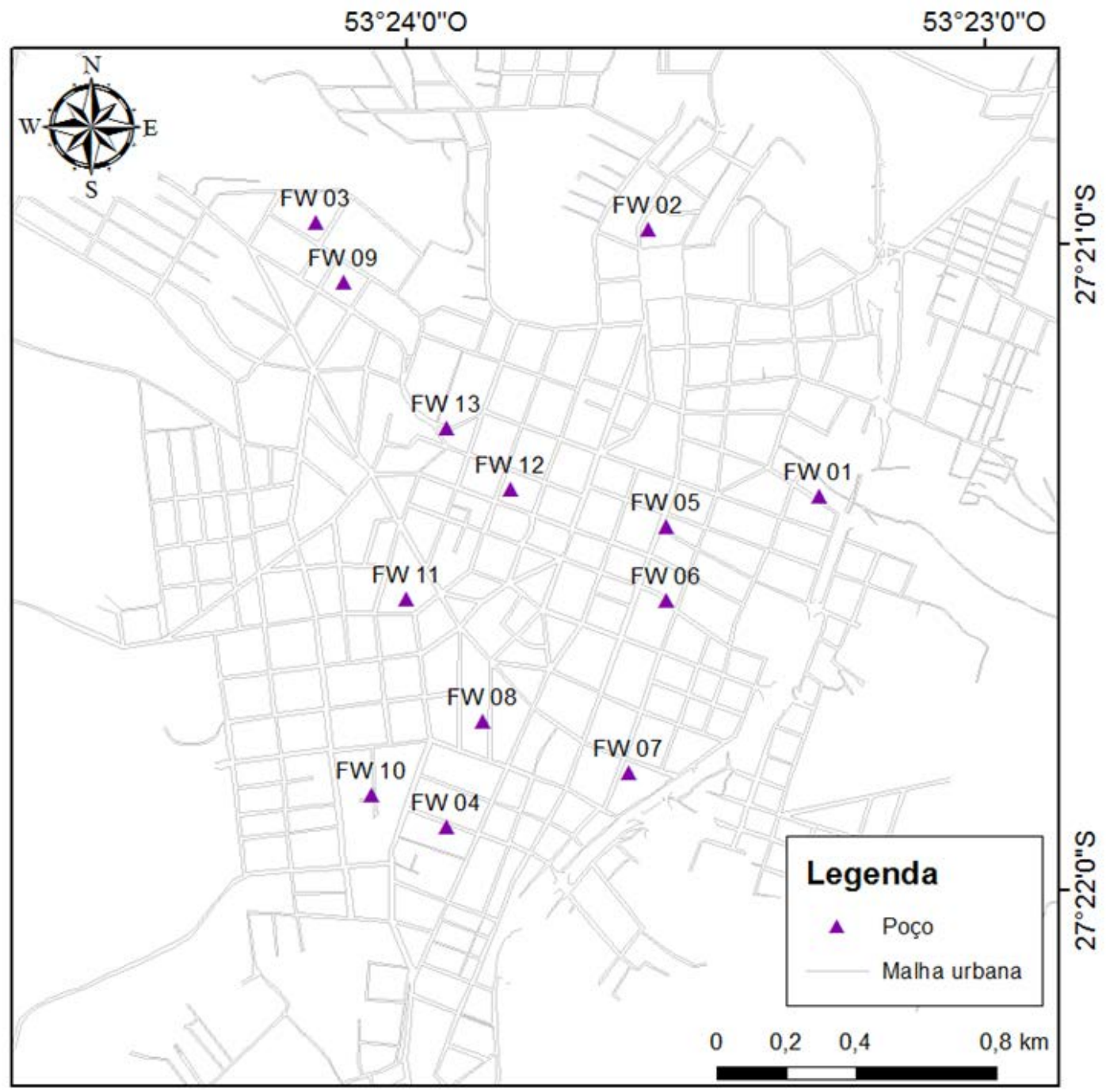

Figura 2 - Localização dos poços de monitoramento na área urbana de Frederico Westphalen. 
Tabela 2 - Localização das nascentes urbanas na cidade de Frederico Westphalen (RS).

\begin{tabular}{cccc}
\hline \multirow{2}{*}{$\begin{array}{c}\text { Nascentes } \\
\text { Urbanas }\end{array}$} & \multicolumn{2}{c}{ UTM 22S* } & \begin{tabular}{c} 
Cota \\
\cline { 2 - 3 } topográfica (m)
\end{tabular} \\
\hline N1 & 263350 & 6972028 & 530 \\
N2 & 263252 & 6972368 & 540 \\
N3 & 262949 & 6972293 & 535 \\
N4 & 262369 & 6972074 & 560 \\
N5 & 262719 & 6970668 & 515 \\
N6 & 262783 & 6971497 & 540 \\
\hline
\end{tabular}

* UTM 22S: Sistema de Projeção Cartográfica.

A localização das nascentes e dos poços utilizados para a elaboração do mapa potenciométrico foi obtida com o auxílio de um GPS (marca Garmin, modelo map76CSx) (Latitude, Longitude) e do mapa de Zoneamento Urbano Especial (Cota Topográfica), sendo que os níveis topográficos foram estimados a partir das curvas de nível de metro em metro, constantes no mapa topográfico cedido pela Prefeitura Municipal de Frederico Westphalen.

A variação do N.A. durante o ano de monitoramento deu origem ao mapa de espessuras de recarga (N.A. máximo - N.A. mínimo), calculadas em metros de coluna de água (m.c.a.). A cartografia hidrogeológica foi elaborada com o auxílio do software ArcGIS 10.1 (ESRI, 2014).

\section{Estimativa da Recarga Direta}

A recarga direta foi calculada utilizando o método WTF. As taxas de recarga foram estimadas a partir da Equação da Recarga, indicada por Healy \& Cook (2002) (Equação 1):

$$
R=S y \frac{d h}{d t}=S y \frac{\Delta h}{\Delta t}=S y . \Delta H(t j)
$$

onde $R(\mathrm{~mm})$ é a recarga, ocorrida entre os tempos t0 e $t j(\Delta \mathrm{t})$; Sy é o rendimento específico e $\Delta H(t j)$ é a diferença entre a cota de elevação do nível d'água no tempo tj e a extrapolação da curva de recessão a partir do tempo to. Meinzer (1923) definiu rendimento específico de um solo (ou rocha) como sendo a proporção do volume d’água que, num solo saturado, é drenada por gravidade em relação ao volume de água total.

O rendimento específico foi calculado a partir da média granulométrica das frações de areia (21\%), silte (33\%) e argila (46\%), obtidas a partir da análise de quinze amostras de solo coletadas na área urbana de Frederico Westphalen (Baum, 2015), conforme tabela 3.
O percentual foi multiplicado pelos rendimentos específicos indicados por Johnson (1967) para cada um dos materiais: $($ Areia $=$ 0,26 , Silte $=0,08$ e Argila $=0,02 ;$ ), para o cálculo de uma média ponderada.

Dessa forma, foi estimado em 0,09 o rendimento específico ( $S y)$ do solo na área de estudo, que se aproxima dos valores médios de macroporosidade do solo $\left(0,12 \mathrm{~m}^{3} \mathrm{~m}^{-3}\right)$ obtidos por Bertollo (2014), a partir ensaios laboratoriais realizados com amostras coletadas a profundidades entre 15 e $40 \mathrm{~cm}$.

Em relação à extrapolação da curva de recessão do nível de água subterrânea, para os casos em que no tempo to o nível d’água extrapolado, resultou em cotas inferiores ao nível freático mínimo observado no poço ao longo do monitoramento (Figura 3) foi adotado, para o cálculo da componente $\Delta H$ da Eq. 1, a diferença entre a cota de elevação do N.A. no tempo tj e o valor mínimo do N.A. observado durante o monitoramento. Nesta simplificação, foi considerado que a cota potenciométrica mínima (N.A.) observada durante o monitoramento é equivalente ao valor mínimo de N.A. da reserva reguladora. Salienta-se que essa simplificação foi aplicada considerando a necessidade de definir um nível de base mínimo de descarga para cada poço de monitoramento, abaixo do qual não foram observadas oscilações de N.A., ou seja, o meio se apresentou permanentemente saturado.

$\mathrm{Na}$ figura 3, encontram-se representados: a cota potenciométrica mínima (N.A. mínimo); a oscilação do N.A. observada no poço de monitoramento; a extrapolação da curva de recessão a partir da cota potenciométrica em $t_{0}$; e a componente $\Delta H$. O cálculo pretende avaliar a reserva reguladora do sistema, que corresponde 
à variação das reservas de água subterrânea no aquífero, ao longo de um ano hidrológico.

Tabela 3 - Textura do solo na área urbana de Frederico Westphalen (RS).

\begin{tabular}{cccccc}
\hline \multirow{2}{*}{ Ponto } & \multicolumn{2}{c}{ Localização UTM 22S } & \multicolumn{3}{c}{ Textura } \\
\cline { 2 - 6 } & Latitude & Longitude & Argila \% & Areia \% & Silte \% \\
\hline $\mathbf{1}$ & 262931,87 & 6971170 & 56,144 & 11,772 & 32,084 \\
$\mathbf{2}$ & 262080,21 & 6971542,72 & 77,886 & 6,012 & 16,102 \\
$\mathbf{3}$ & 262889,84 & 6972264,08 & 44,777 & 17,017 & 38,206 \\
$\mathbf{4}$ & 263202,35 & 6971512,22 & 14,415 & 64,062 & 21,522 \\
$\mathbf{5}$ & 263721,45 & 6972359,54 & 48,428 & 19,155 & 32,417 \\
$\mathbf{6}$ & 262356,98 & 6972282,43 & 49,845 & 19,333 & 30,822 \\
$\mathbf{7}$ & 262711,87 & 6969938,93 & 57,052 & 10,180 & 32,769 \\
$\mathbf{8}$ & 262819,29 & 6972303,41 & 40,495 & 19,110 & 40,395 \\
$\mathbf{9}$ & 263541,15 & 6972097,66 & 17,823 & 58,192 & 23,985 \\
$\mathbf{1 0}$ & 262765,34 & 6971335,86 & 38,405 & 23,889 & 37,705 \\
$\mathbf{1 1}$ & 262618,75 & 6972291,68 & 54,006 & 8,912 & 37,082 \\
$\mathbf{1 2}$ & 262494,49 & 6970294,5 & 35,828 & 20,606 & 43,566 \\
$\mathbf{1 3}$ & 262156,54 & 6971721,8 & 52,970 & 13,301 & 33,729 \\
$\mathbf{1 4}$ & 262838,73 & 6971910,22 & 54,039 & 12,231 & 33,730 \\
$\mathbf{1 5}$ & 263290,35 & 6972002,49 & 54,691 & 10,190 & 35,120 \\
\hline
\end{tabular}

Fonte: Adaptado Baum (2015).

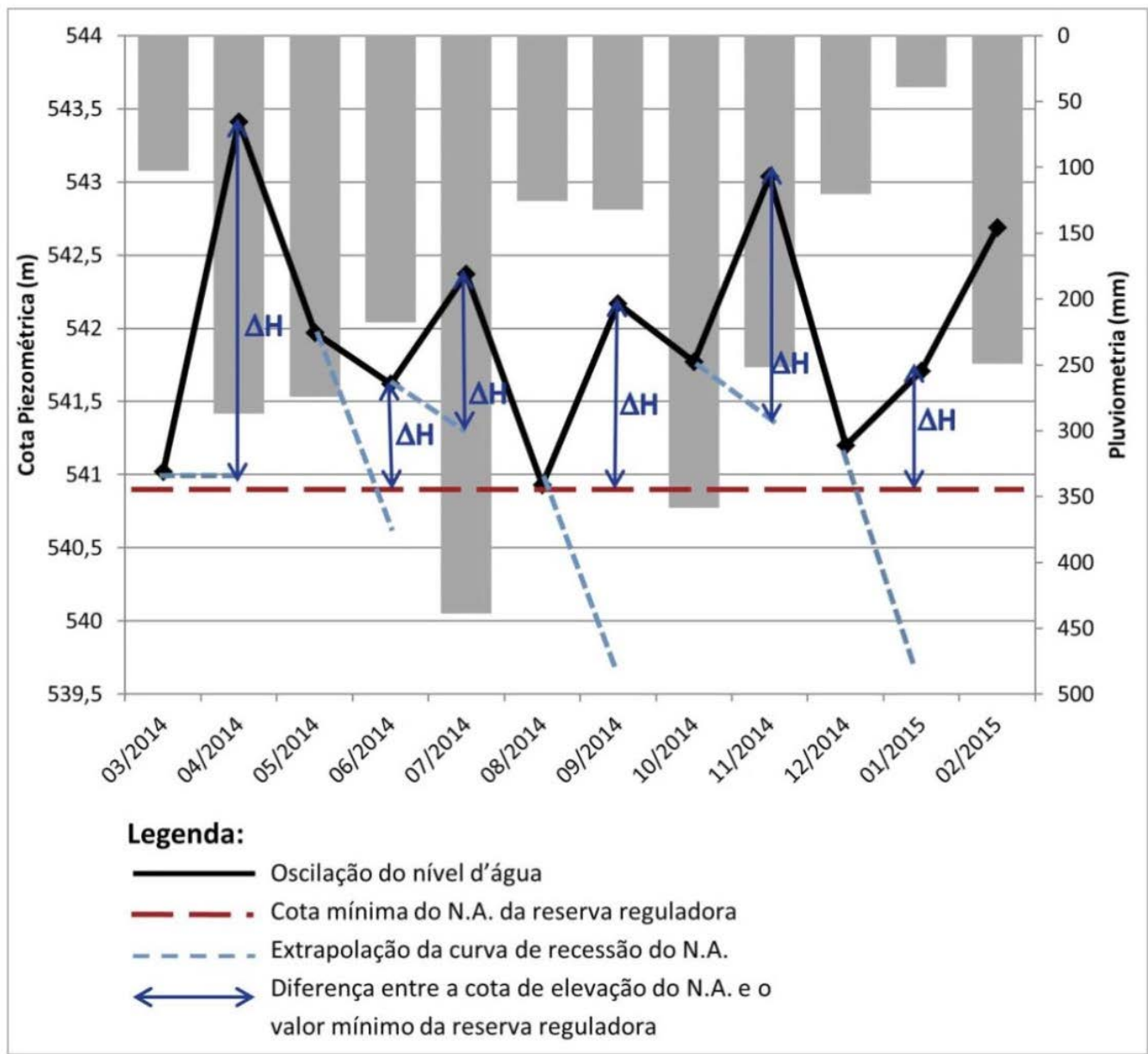

Figura 3 - Análise do hidrograma FW13 com a extrapolação das curvas de recessão e a medição das alturas de recarga $\left(\Delta H=H_{t j}-H_{t 0}\right)$ considerando como base da reserva reguladora o valor mínimo de N.A. observado durante o monitoramento hidrológico. 


\section{RESULTADOS E DISCUSSÕES}

Entre fevereiro de 2014 e fevereiro de 2015 o comportamento pluviométrico se apresentou incomum para a região, tendo registrado eventos extremos no mês de julho e setembro/outubro de 2014, o que provocou uma elevada variabilidade sazonal da pluviometria (Tabela 4).

Tabela 4 - Precipitação observada na Estação Meteorológica Automática de Frederico Westphalen (RS), entre 02/2014 e 02/2015.

\begin{tabular}{ccc}
\hline $\begin{array}{c}\text { Período (10/02/2014 a } \\
\mathbf{1 7 / 0 2 / 2 0 1 5})\end{array}$ & $\begin{array}{c}\text { Data de monitoramento do } \\
\text { nível freático }\end{array}$ & $\begin{array}{c}\text { Precipitação total } \\
\text { no período (mm) }\end{array}$ \\
\hline $10 / 02-13 / 03$ & $13 / \mathrm{mar} / 14$ & 146,60 \\
$14 / 03-15 / 04$ & $15 / \mathrm{abr} / 14$ & 358,00 \\
$16 / 04-09 / 05$ & $09 / \mathrm{mai} / 14$ & 159,20 \\
$10 / 05-12 / 06$ & $12 / \mathrm{jun} / 14$ & 218,00 \\
$13 / 06-11 / 07$ & $11 / \mathrm{jul} / 14$ & 438,60 \\
$12 / 07-15 / 08$ & $15 / \mathrm{ago} / 14$ & 151,80 \\
$16 / 08-13 / 09$ & $13 / \mathrm{set} / 14$ & 107,22 \\
$14 / 09-13 / 10$ & $13 /$ out $/ 14$ & 358,20 \\
$14 / 10-10 / 11$ & $10 / \mathrm{nov} / 14$ & 250,60 \\
$11 / 11-15 / 12$ & $15 / \mathrm{dez} / 14$ & 122,40 \\
$16 / 12-09 / 01$ & $09 / \mathrm{jan} / 15$ & 37,00 \\
$10 / 01-17 / 02$ & $17 / \mathrm{fev} / 15$ & 249,20 \\
\hline
\end{tabular}

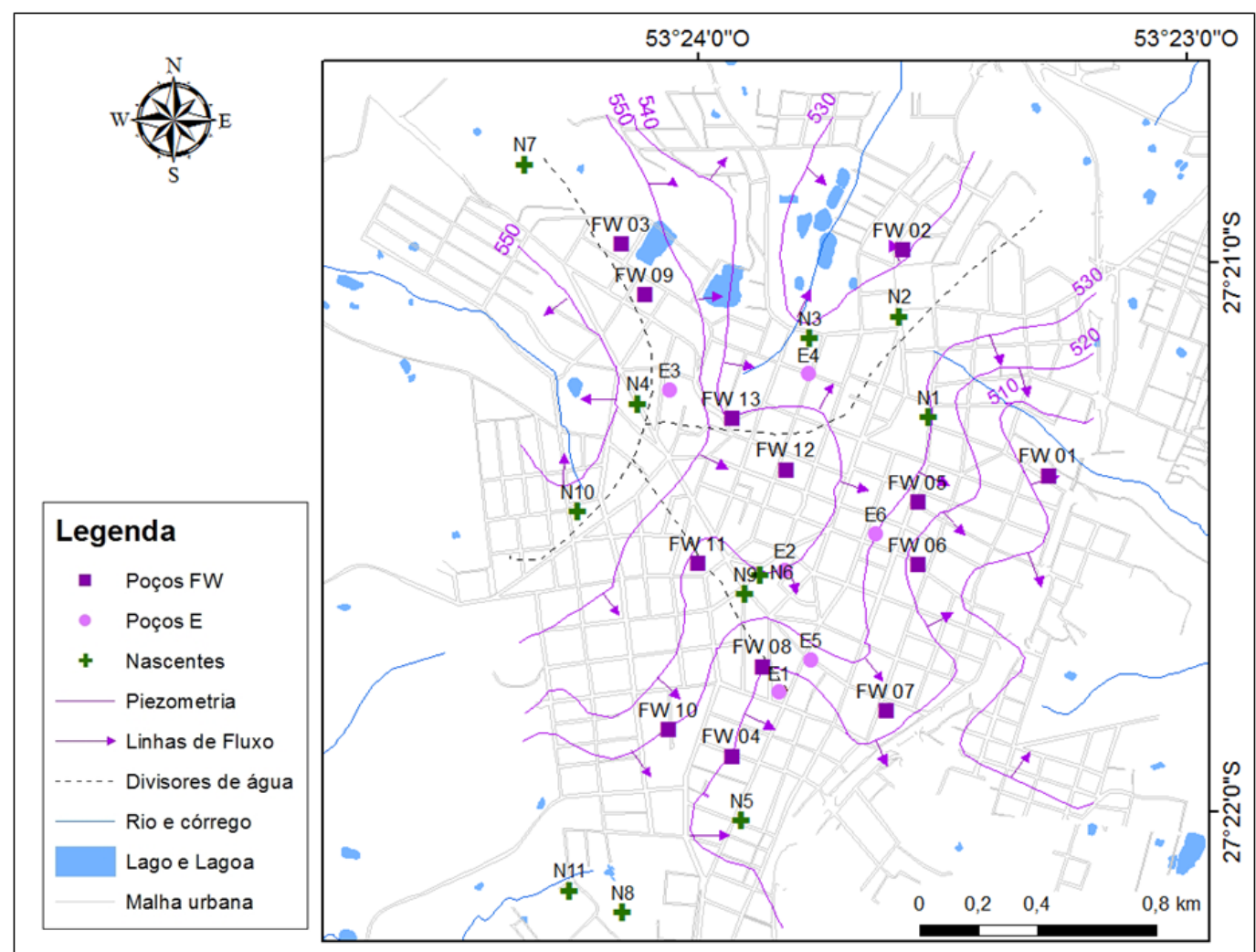

Figura 4 - Mapa de piezometria em metros e de fluxo das águas subterrâneas do aquífero freático subjacente à área urbana de Frederico Westphalen (RS). Data da medição do N.A.: outubro de 2014.

Os meses de setembro, junho e abril registraram precipitação mais de $100 \mathrm{~mm}$ acima da média (entre 2012 e 2016), enquanto os meses de outubro e dezembro registraram precipitação com pelo menos $100 \mathrm{~mm}$ abaixo da média (entre 2012 e 2016).

O total pluviométrico registrado no período de estudo foi de 2.596,8 $\mathrm{mm}$, que é aproximadamente $8 \%$ acima da média, sendo esta da ordem de $2.400 \mathrm{~mm}$. 
O aquífero livre estudado é subjacente aos divisores de água superficiais de quatro bacias hidrográficas.

O mapa potenciométrico do aquífero apresenta cotas entre $550 \mathrm{~m}$ e $510 \mathrm{~m}$ de altitude (Figura 4), com valor mínimo de 504,28 m (FW01) e máximo de 557,89 m (FW09), medidas em outubro de 2014.

Constata-se que a área urbana se encontra sobre divisores de águas subterrâneas, e que as águas do aquífero livre se dirigem para Norte, Oeste e Leste, predominantemente, concentrando-se na direção das nascentes e dos cursos de água superficiais.

A variação máxima da espessura saturada do aquífero, estimada a partir da diferença entre o
N.A. máximo e o N.A. mínimo observado entre 10/02/2014 e 17/02/2015, foi de 0,12 a 2,48 m (FW03 e FW13 respectivamente). Os poços de monitoramento localizados próximos às áreas de descarga do aquífero livre, como nascentes, córregos e lagoas, apresentaram as menores amplitudes de variação do nível freático durante o período de monitoramento: FW03 $(0,12 \mathrm{~m})$, FW05 (0,17 m), FW01 (0,34 m), FW02 (0,34 m) e FW06 (0,36 m).

As maiores amplitudes entre o N.A. máximo e o N.A. mínimo foram observadas nos poços FW13 (2,48 m), FW11 (2,37 m) e FW12 (2,22 $\mathrm{m})$, que estão localizados sobre os divisores de água e apresentaram os níveis freáticos mais profundos (Figura 5).

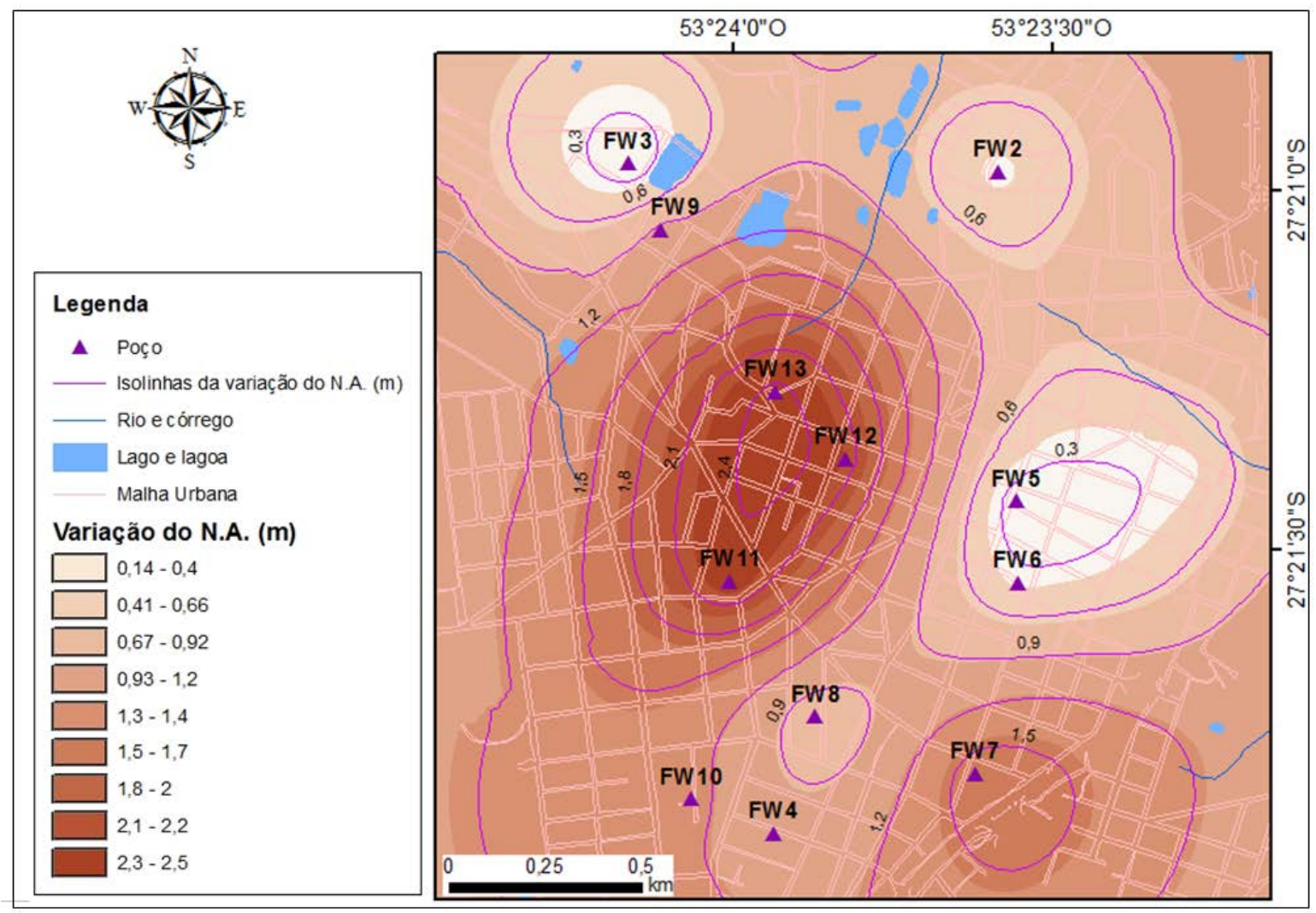

Figura 5 - Espacialização da variação máxima do N.A. (altura da espessura saturada) entre fev./2014 e fev./2015, na área urbana de Frederico Westphalen (RS).

A taxa de recarga foi estimada mensalmente, para cada poço, através da aplicação da Equação 1, considerando o Sy de 0,09, para toda a área urbana e a variação do N.A. $(\Delta H)$ e a precipitação mensal $\left(\mathrm{P}_{\mathrm{m}}\right)$. A partir da taxa de recarga mensal $\left(R_{m}\right)$ foi calculada a recarga anual $\left(R_{a}\right)$ e o percentual de recarga anual em relação à precipitação total registrada $(\mathrm{RP})$ por poço, para o período entre 02/2014 e 02/2015 (Tabela 5).
Os períodos em que ocorreram os maiores níveis precipitados foram: de 14/03 a 15/04 (358 mm), 13/06 a 11/07 (438 mm) e 14/09 a 10/11 (358 mm). A ausência de registro de recarga no mês de março deve-se à ausência de dados prévios para a realização de cálculos, por esse motivo foram igualmente desconsiderados os dados de precipitação de março nos cálculos da recarga total no período em relação a precipitação, sendo adotada a precipitação total 
de 2450,22 mm no período monitorado. No mês de dezembro também não houve registro de recarga em nenhum poço monitorado, justificado pelo declínio dos níveis d’água subterrânea, indicando predominância de descarga do aquífero (recessão da curva de N.A.).

A recarga anual média, entre os 13 poços monitorados, foi de $283,58 \mathrm{~mm}$, correspondendo a $11,57 \%$ do total de $2.450,22 \mathrm{~mm} / \mathrm{ano}$ precipitado. Apesar da recarga média da área urbana de Frederico Westphalen indicar um valor um pouco acima de $10 \%$ do total precipitado, a variabilidade temporal (Figura 4) e espacial deste parâmetro é significativa (Tabela 5).

A análise das médias mensais indica valores de recarga de 0\% (dez/2014) (onde predomina a recessão da curva de N.A.), atingindo até $103 \%$ (jan/2015) do total precipitado (Figura 6). No mesmo período de medição, alguns poços apresentaram recarga e outros não (Tabela 5), como é o exemplo do mês de maio/2014, quando apenas o FW5 apresentou elevação do N.A. em relação à campanha anterior.

Tabela 5 - Taxa de recarga natural mensal e anual do aquífero subjacente à área urbana de Frederico Westphalen (RS), calculada pelo Método WTF para o período de 02/2014 a 02/2015.

\begin{tabular}{|c|c|c|c|c|c|c|c|c|c|c|c|c|c|c|c|}
\hline \multirow{2}{*}{ Poço } & \multirow{2}{*}{$\begin{array}{c}\Delta H \\
\text { (m/ano) }\end{array}$} & \multicolumn{12}{|c|}{ Recarga mensal (Rm) (mm/mês) } & \multirow{2}{*}{$\begin{array}{c}\text { Recarga } \\
\text { anual (Ra) } \\
\text { (mm/ano) }\end{array}$} & \multirow{2}{*}{$\begin{array}{l}\text { RP } \\
\text { (\%) }\end{array}$} \\
\hline & & $\operatorname{mar} / 14$ & abr/14 & mai/14 & jun/14 & jul/14 & ago/14 & set/14 & out $/ 14$ & nov/14 & $\operatorname{dez} / 14$ & jan/15 & fev/15 & & \\
\hline FW01 & 0,69 & 0,0 & 1,8 & 0,0 & 7,2 & 0,0 & 0,0 & 12,2 & 0,0 & 14,0 & 0,0 & 2,7 & 24,3 & 62,1 & 2,53 \\
\hline FW02 & 1,15 & 0,0 & 2,7 & 0,0 & 16,2 & 0,0 & 3,6 & 26,1 & 0,0 & 25,2 & 0,0 & 29,7 & 0,0 & 103,5 & 4,22 \\
\hline FW03 & 0,34 & 0,0 & 3,6 & 0,0 & 0,0 & 3,6 & 0,0 & 7,2 & 0,0 & 7,2 & 0,0 & 4,5 & 4,5 & 30,6 & 1,25 \\
\hline FW04 & 2,2 & 0,0 & 90,5 & 0,0 & 63,0 & 0,0 & 14,4 & 38,7 & 0,0 & 0,0 & 0,0 & 36,9 & 0,0 & 243,5 & 9,94 \\
\hline FW05 & 0,34 & 0,0 & 0,0 & 6,3 & 0,0 & 3,6 & 0,0 & 0,0 & 0,0 & 11,7 & 0,0 & 9,0 & 0,0 & 30,6 & 1,25 \\
\hline FW06 & 0,71 & 0,0 & 6,3 & 0,0 & 14,4 & 0,0 & 6,3 & 0,0 & 0,0 & 4,5 & 0,0 & 25,2 & 7,2 & 63,9 & 2,61 \\
\hline FW07 & 4,6 & 0,0 & 4,5 & 0,0 & 105,6 & 7,2 & 0,0 & 97,2 & 0,0 & 96,3 & 0,0 & 32,4 & 97,2 & 440,4 & 17,97 \\
\hline FW08 & 1,57 & 0,0 & 10,8 & 0,0 & 0,0 & 18,0 & 0,0 & 18,0 & 0,0 & 29,7 & 0,0 & 22,5 & 42,3 & 141,3 & 5,77 \\
\hline FW09 & 1,49 & 0,0 & 0,0 & 0,0 & 0,0 & 1,8 & 0,0 & 30,6 & 0,0 & 50,4 & 0,0 & 20,7 & 30,6 & 134,1 & 5,47 \\
\hline FW10 & 4,21 & 0,0 & 117,0 & 0,0 & 29,7 & 17,1 & 0,0 & 57,6 & 0,0 & 56,7 & 0,0 & 52,2 & 48,6 & 378,9 & 15,46 \\
\hline FW11 & 6,85 & 0,0 & 211,5 & 0,0 & 9,0 & 49,5 & 0,0 & 99,0 & 0,0 & 153,0 & 0,0 & 94,5 & 0,0 & 616,5 & 25,16 \\
\hline FW12 & 6,42 & 0,0 & 222,0 & 0,0 & 76,5 & 99,6 & 0,0 & 81,0 & 32,4 & 32,4 & 0,0 & 105,3 & 9,0 & 658,2 & 26,86 \\
\hline FW13 & 8,7 & 0,0 & 216,0 & 0,0 & 54,0 & 97,2 & 0,0 & 106,2 & 0,0 & 151,2 & 0,0 & 63,0 & 95,4 & 783,0 & 31,96 \\
\hline \multicolumn{2}{|c|}{ Precipitação } & $* * *$ & 358,0 & 159,2 & 218,0 & 438,6 & 151,8 & 107,2 & 358,2 & 250,6 & 122,4 & 37,0 & 249,2 & & \\
\hline
\end{tabular}

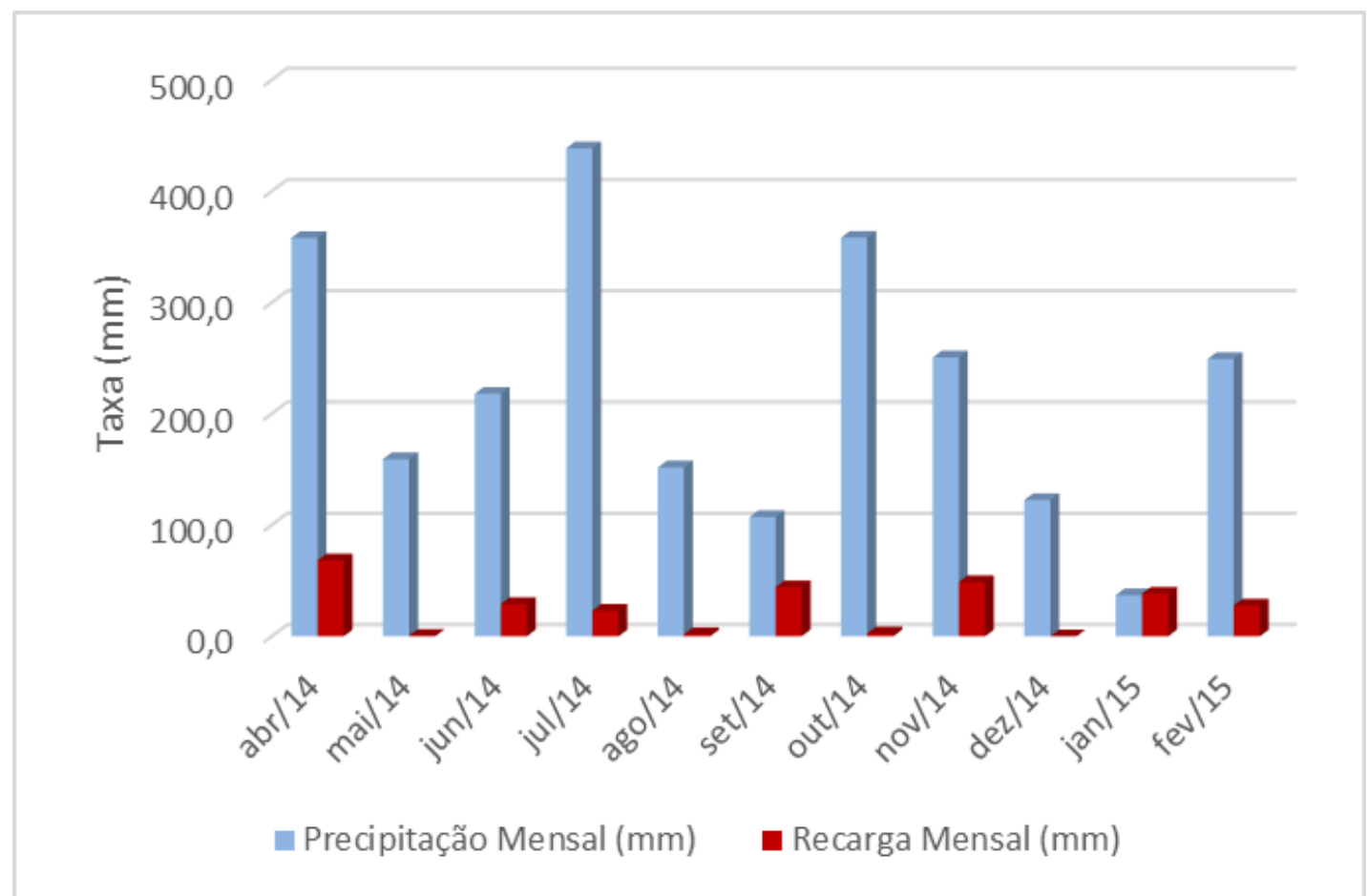

Figura 6 - Precipitação e recarga mensal do aquífero livre na área urbana de Frederico Westphalen, entre 02/2014 e $02 / 2015$. 
Para avaliar a sensibilidade da recarga do aquífero à ocorrência, ou ausência, de precipitação nos dias antecedente à medição do N.A., foram calculados, para cada poço, os coeficientes de correlação, obtidos pelo método linear, entre: a) a precipitação dos 10 dias antecedentes à medição de N.A. e a recarga; b) o número de dias sem precipitação (entre os 10 dias antecedentes à medição do N.A.) e a recarga; e c) a precipitação total do período entre medições e a recarga (Tabela 7). As informações utilizadas para obtenção dos coeficientes estão apresentadas na tabela 6 .

A análise da sensibilidade da recarga do aquífero na área urbana de Frederico Westphalen à ocorrência de precipitação nos dez dias antecedentes a medição do N.A. apresentou maior correlação positiva $(0,61 ; 0,56$ e 0,35$)$ nos poços localizados em zona com maior profundidade do N.A. (FW11, FW13 e FW12, respectivamente). A grande maioria dos poços não apresentaram correlação significativa entre a recarga e o somatório da precipitação dos dez dias prévios à medição do N.A.

Em relação à ausência de precipitação nos dez dias prévios à medição, nos poços FW1 e FW7 foi observada sensibilidade à ausência de precipitação nos dez dias prévios à medição, com correlação negativa de $-0,70$ e $-0,63$ respectivamente, entre a recarga mensal e o número de dias sem precipitação, anteriores à medição do N.A.

Tabela 6 - Valores de Precipitação e ausência de precipitação observada na Estação Meteorológica Automática de Frederico Westphalen (RS), entre 02/2014 e 02/2015.

\begin{tabular}{|c|c|c|c|c|c|}
\hline $\begin{array}{c}\text { Período } \\
(10 / 02 / 2014 \text { a } \\
17 / 02 / 2015) \\
\end{array}$ & $\begin{array}{c}\text { Data de } \\
\text { monitoramento do } \\
\text { nível freático } \\
\end{array}$ & $\begin{array}{c}\text { Precipitação (mm) nos dez dias } \\
\text { antecedente à data de } \\
\text { monitoramento }\end{array}$ & $\begin{array}{c}\text { Dias ausentes } \\
\text { de } \\
\text { precipitação* }\end{array}$ & $\begin{array}{c}\text { Precipitação } \\
\text { total no período } \\
\text { (mm) }\end{array}$ & $\begin{array}{c}\text { Recarga } \\
\text { (Média dos } \\
\text { poços) Mensal }\end{array}$ \\
\hline $10 / 02-13 / 03$ & 13/mar/14 & 131,60 & 4 & 146,60 & 0,00 \\
\hline $14 / 03-15 / 04$ & 15/abr/14 & 252,00 & 7 & 358,00 & 68,21 \\
\hline $16 / 04-09 / 05$ & 09/mai/14 & 146,20 & 5 & 159,20 & 0,48 \\
\hline $10 / 05-12 / 06$ & 12/jun/14 & 21,60 & 3 & 218,00 & 28,89 \\
\hline $13 / 06-11 / 07$ & 11/jul/14 & 29,60 & 6 & 438,6 & 22,89 \\
\hline $12 / 07-15 / 08$ & 15/ago/14 & 27,00 & 5 & 151,80 & 1,87 \\
\hline 16/08 - 13/09 & $13 /$ set/14 & 37,60 & 3 & 107,22 & 44,13 \\
\hline $14 / 09-13 / 10$ & 13/out/14 & 29,20 & 6 & 358,20 & 2,49 \\
\hline $14 / 10-10 / 11$ & 10/nov/14 & 182,20 & 3 & 250,60 & 48,63 \\
\hline $11 / 11-15 / 12$ & 15/dez/14 & 4,60 & 6 & 122,40 & 0,00 \\
\hline 16/12 - 09/01 & 09/jan/15 & 0,40 & 9 & 37,00 & 38,35 \\
\hline 10/01 - 17/02 & 17/fev/15 & 52,60 & 2 & 249,20 & 27,62 \\
\hline
\end{tabular}

* Dias ausentes de precipitação nos dez dias antecedente à data de monitoramento.

Tabela 7 - Coeficientes de correlação relacionados a Precipitação e Recarga.

\begin{tabular}{cccc}
\hline Poço & $\begin{array}{c}\text { Correlação Precipitação } \\
\text { antecedente/Recarga }\end{array}$ & $\begin{array}{c}\text { Correlação Ausência de } \\
\text { Precipitação/Recarga }\end{array}$ & $\begin{array}{c}\text { Correlação Precipitação } \\
\text { (mensal)/Recarga }\end{array}$ \\
\hline FW01 & 0,02 & $-0,70$ & $-0,03$ \\
FW02 & $-0,11$ & 0,02 & $-0,45$ \\
FW03 & 0,19 & $-0,22$ & 0,03 \\
FW04 & 0,27 & 0,29 & 0,03 \\
FW05 & 0,22 & 0,18 & $-0,14$ \\
FW06 & $-0,23$ & 0,41 & $-0,36$ \\
FW07 & $-0,09$ & $-0,63$ & $-0,12$ \\
FW08 & 0,06 & $-0,30$ & 0,10 \\
FW09 & 0,11 & $-0,45$ & $-0,17$ \\
FW10 & 0,52 & 0,22 & 0,19 \\
FW11 & 0,61 & 0,22 & 0,19 \\
FW12 & 0,35 & 0,47 & 0,37 \\
FW13 & 0,56 & $-0,05$ & 0,40 \\
\hline
\end{tabular}


No geral a recarga mensal por poço teve correlação (positiva e negativa) mediana à fraca com a precipitação mensal, conforme apresentado na tabela 7 e observado na figura 6 . Um dos fatores que explicam esse resultado é a área urbana possuir diversas áreas naturais de descarga do aquífero (as nascentes, córregos).

Delin et al. (2007) afirmam que, dentre as limitações do método WTF, a variação de nível d’água em determinado ponto só é representativa dentro do divisor de águas em que o mesmo se encontra.

A impermeabilização do solo também diminui as taxas de infiltração da precipitação e, consequentemente, a recarga.

Sendo avaliada no estudo apenas a recarga do sistema originada de fontes não contínuas, como a precipitação, as taxas de impermeabilização do solo na área urbana de Frederico Westphalen (de 70\%), implicam em um impacto negativo para a recarga, causado pela urbanização.

Diversos estudos detalhados sobre recarga indicam a relação entre a taxa de precipitação e a recarga de um aquífero, e compreendem estimativas de taxas de recarga natural entre 5\% e $25 \%$ do total precipitado (Lerner, 1990).

Os resultados da razão entre a recarga obtida na área urbana de Frederico Westphalen e a precipitação do mesmo período foi de 1,25\% (FW03 e FW 05) à 31,96\% (FW13), de acordo com o poço, e se assemelham aos resultados encontrados por Martelli (2012) (25\%) e Maziero \& Wendland (2008) (16,5\%).

A variabilidade espacial da taxa de recarga na área urbana é elevada, entre 1,25\% e 31,96\% da precipitação, e é afetada pela proximidade das áreas naturais de descarga do aquífero (as nascentes), as quais apresentam baixas taxas de recarga, e pela localização em áreas com maior espessura da zona não saturada, nos divisores de água subterrânea, onde foram verificadas as maiores taxas de recarga.

Maziero \& Wendland (2008) concordam em que a indicação de um valor médio de recarga calculado para uma determinada área, considerando dados de vários pontos de monitoramento hidrogeológico, é questionável, visto a variabilidade dos resultados pontuais.

Os resultados deste estudo também estão de acordo com essa afirmativa, conforme pode ser verificado na tabela 5, que apresenta a variabilidade pontual da recarga, e na figura 7, que apresenta a correlação entre o percentual de recarga anual (em relação à precipitação) e a profundidade máxima do nível d’água subterrânea do aquífero livre para cada poço.

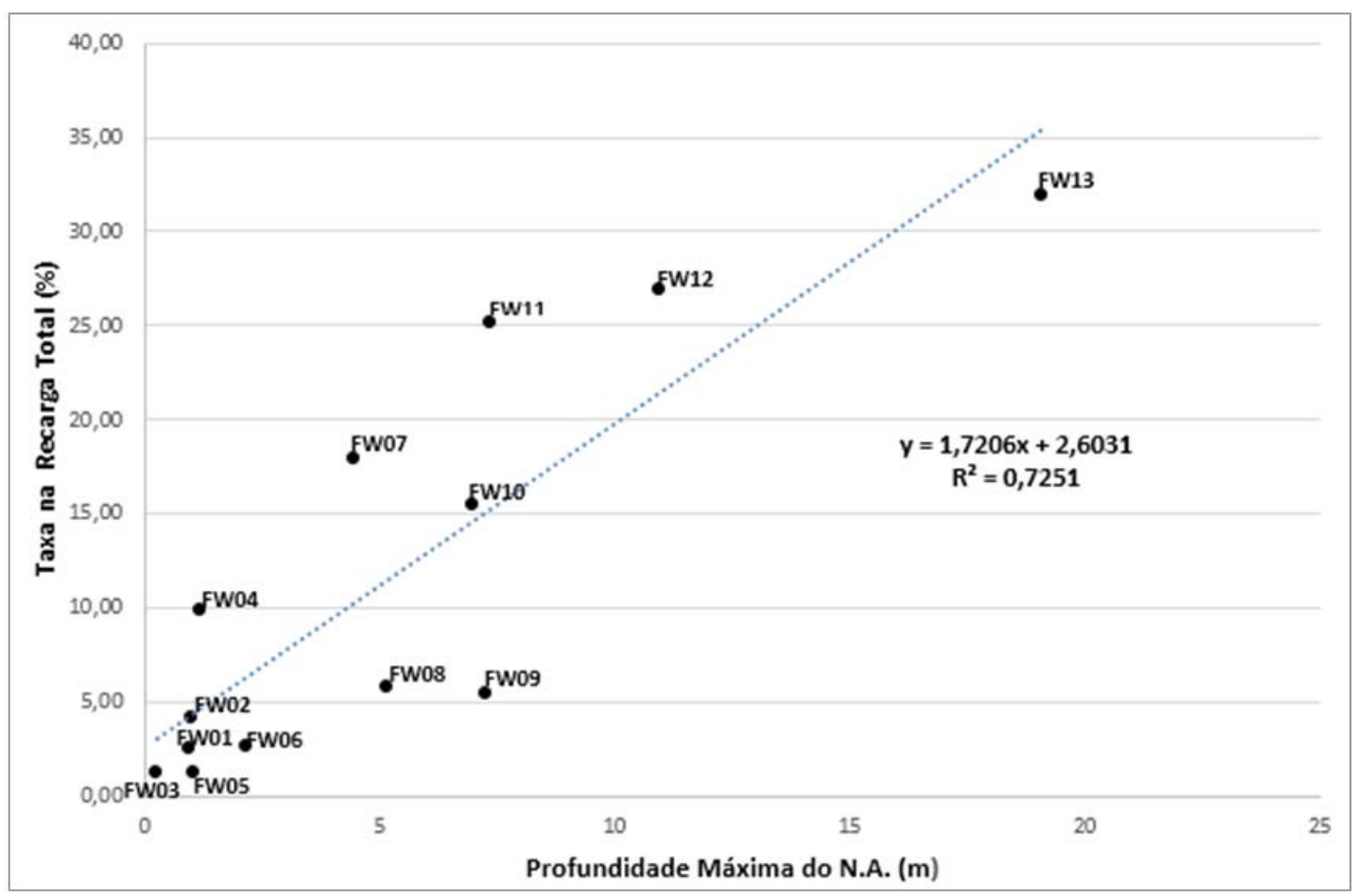

Figura 7 - Correlação entre o percentual de recarga anual (em relação à precipitação) e a profundidade máxima do nível d'água subterrânea do aquífero livre, em 13 poços de monitoramento localizados na zona urbana de Frederico Westphalen (RS). 
O coeficiente de correlação entre a taxa de recarga de cada poço e a profundidade máxima do nível d'água é 0,7 , indicando um elevado grau de dependência entre as variáveis de armazenamento de água e a espessura do meio não saturado. Em análise semelhante, Maziero \& Wendland (2008) observaram que não existe uma correlação única entre esses parâmetros. A observação de que as altas taxas de recarga ocorridas nos pontos FW11, FW12 e FW13, que estão localizados em altitudes maiores, está de acordo com as observações de Healy \& Cook (2002) que explicam o fato considerando que em regiões úmidas as maiores taxas de recarga são normalmente observadas em altitudes maiores e as descargas em altitudes menores.

Em um contexto geral as áreas com maior espessura da camada não saturada, próximas a divisores de águas e distantes de áreas de descarga apresentaram grande potencial de recarga direta de origem natural e armazenamento de água subterrânea. Apesar do potencial de recarga, essas mesmas áreas, conforme Baum (2015), devido às altas taxas de impermeabilização e elevada altitude são agravantes de alagamentos em bairros periféricos, de menor altitude, devido ao escoamento superficial, o que acaba interferindo negativamente na recarga. Em análise conjunta entre áreas com maior potencial de recarga e áreas que necessitam com maior urgência de práticas que aumentem a taxa de infiltração, as áreas de divisores de água, localizados nas proximidades dos poços FW07, FW10, FW11, FW12 e FW 13 se apresentam como áreas potenciais.

\section{CONCLUSÕES}

A recarga direta estimada através do método WTF, na área urbana de Frederico Westphalen foi de $283,58 \mathrm{~mm} / \mathrm{ano}$, correspondendo a $11,57 \%$ da precipitação total $(2.450 \mathrm{~mm})$.

Constatou-se que a resposta do aquífero à precipitação varia em função da localização do ponto de monitoramento (variabilidade espacial) e da variabilidade temporal da precipitação (em dias prévios à medição, período sem precipitação, altura precipitada; total mensal precipitado, etc.).

A análise da variabilidade temporal da recarga indicou que os poços localizados em zona com maior profundidade do N.A. e próximos aos divisores d'água subterrânea possuem influência significativamente positiva nos níveis de recarga, bem como a influência da precipitação em períodos prévios às medições.

Em relação ausência de precipitação nos dias prévios à medição foi observada elevada sensibilidade, sendo recomendável que se faça monitoramento contínuo, com intervalos de tempo menores, a fim de avaliar a variabilidade da recarga em função da variabilidade da precipitação em curto espaço de tempo.

A recarga apresentou alta variabilidade espacial na área de estudo, sendo que os poços que apresentaram menor variação do N.A. no período estão localizados próximos a nascentes e cursos d'água, o que pode ser devido à velocidade de descarga ser maior do que a periodicidade de medições de N.A.

Esse fato sugere que o tempo de resposta do sistema é curto, o que implicaria em curto tempo de retenção das águas de recarga na zona de intemperismo da Formação Serra Geral.

Apesar das características do solo local não serem as mais favoráveis à infiltração, devido ao alto teor de argila, as altas taxas de impermeabilização da área (70\%) possivelmente foram um dos principais fatores responsáveis pela baixa taxa de recarga, em correspondência à precipitação total, fato esse que demostra a necessidade de políticas de gestão do uso e ocupação do solo em espaços urbanos que viabilizem áreas com usos que permitam a infiltração da precipitação.

$\mathrm{Na}$ área urbana de Frederico Westphalen as áreas com maior potencial para implantação de projetos são as áreas localizadas próximas aos divisores de água, as quais apresentaram boa capacidade de armazenamento de água subterrânea, além de serem áreas com potencial agravante para alagamentos e inundações quando altamente impermeabilizadas.

\section{REFERÊNCIAS}

ARBOIT, N.K.S. Proposta de implementação de microrreservatório de detenção em lotes na cidade de Frederico Westphalen. Frederico Westphalen, 2014. 73 p. Trabalho de Conclusão de Curso (Curso de Engenharia
Ambiental e Sanitária) - Universidade Federal de Santa Maria. BAUM, C.A. Estimativa da recarga de aquífero freático na área urbana de Frederico Westphalen. Frederico Westphalen, 2015. 71p. Trabalho de Conclusão de Curso 
(Graduação em Engenharia Ambiental e Sanitária)Universidade Federal de Santa Maria.

BERNARDI, I.P.; PULCHÉRIO-LEITE, A.; MIRANDA, J.; PASSOS, F.C. Ampliação da distribuição de Molossopsneglectus Williams e Genoways (Chiroptera, Molossidae) para o Sul da América do Sul. Revista Brasileira de Zoologia, v. 24, n. 2, p. 505-507, 2007.

BERTANI, G.; BREUNIG, F.M.; SPOHR, R.B. Análise de crescimento da mancha urbana do município de Frederico Westphalen, RS-Brasil através de imagens Landsat 5 TM. Revista Geografar, v. 7, n. 1, p. 68-83, 2012.

BERTOLLO, A.M. Propriedades físicas de um latossolo após calagem, gessagem em manejos de solo. Frederico Westphalen, 2014. 99p. Dissertação de Mestrado (PósGraduação em Agronomia - Agricultura e Ambiente) Universidade Federal de Santa Maria.

DELIN, G.N.; HEALY, R.W.; LORENZ, D.L.; NIMMO, J.R. Comparison of local-to regional-scale estimates of groundwater recharge in Minnesota, USA, Journal of Hydrology, v. 334, n. 1, p. 231-249, 2007.

FAVERO, E. A seca na vida das famílias rurais de Frederico Westphalen - RS. 2006, 136p. Dissertação (Mestrado Extensão Rural) - Universidade Federal de Santa Maria, Santa Maria, 2006.

FEITOSA, F.A.C. Hidrogeologia: Conceitos e aplicações, Rio de Janeiro: CPRM: LABHID, 812p., 2008.

FLORES, B.A. Características da taxa de infiltração e densidade do solo em distintos tipos de cobertura de solo em zona urbana. Frederico Westphalen, 2013. 37p. Trabalho de Conclusão de Curso (Graduação em Engenharia Ambiental e Sanitária) - Universidade Federal de Santa Maria.

HEALY, R.W. Estimating groundwater recharge. Cambridge Univ. Press, 238p., 2010.

HEALY, R.W. \& COOK, P.G. Using ground-water levels to estimate recharge. Hydrogeology Journal, v. 10, p.10, p. 91 - 109, 2002.

HIBBS, B.J. \& SHARP, J.M. Jr. Hydrogeological impacts of urbanization. Environmental \& Engineering Geoscience, v. 18, n. 1, p. 3-24, 2012.

JOHNSON, A.I. Specific yield - Compilation of specific yields for various materials, U.S. Geological Survey WaterSupply Paper, 1967.

LERNER, D.N. Identifying and quantifying urban: a review. Hidrogeology Journal, v. 10, n. 1, p. 143 - 152, 2002.

LERNER, D.N. Groundwater recharge in urban areas. Atmos Environ, v. 24B, n.1, p. 29 - 33, 1990.

LIMA, G.C.; SILVA, M.L.N.; CURI, N.; SILVA, M.A.; OLIVEIRA, A.H.; AVANZI, J.C.; FREITAS, D.A.F. Estimativa do potencial de recarga na sub-bacia das Posses, Extrema (MG), em função dos atributos fisiográficos, pedológicos e topográficos. Unesp, Geociências, v. 32, n. 1, p. 51-62, 2013.

MACHADO, J.L.F. \& FREITAS, M.A. Projeto Mapa Hidrogeológico do Rio Grande do Sul. Porto Alegre: CPRM, 2005.

MARTELLI, G.V. Monitoramento da flutuação dos níveis de água em aquíferos freáticos para avaliação do potencial de recarga em área de afloramento do Sistema Aquífero Guarani em Cacequi - RS. Santa Maria, 2012. 151p. Dissertação (Mestrado em Engenharia Civil e Ambiental) Universidade Federal de Santa Maria.

MAZIERO, T.A. \& WENDLAND, E. Variabilidade Espacial da Recarga em Área Urbana. Revista Brasileira de Recursos Hídricos, v. 13, n. 3, p. 35 - 46, 2008.

WENDLAND, E.; GOMES, L.H.; TROEGER, U. Recharge contribution to the Guarani Aquifer System estimated from the water balance method in a representative watershed. Anais da Academia Brasileira de Ciências, v. 87, n. 2, p. 595 - 609, 2015.

USGS - Groundwater Resource Program. Water-Table Fluctuations Method, Available, 2007

Submetido em 9 de outubro de 2016 Aceito em 20 de novembro de 2017 